\title{
Assessment of Iranian Nurses' Knowledge and Anxiety Toward COVID-19 During the Current Outbreak in Iran
}

\author{
Marzieh Nemati ${ }^{1}$, Bahareh Ebrahimi ${ }^{2,{ }^{*}}$ and Fatemeh Nemati ${ }^{3}$ \\ ${ }^{1}$ Endocrinology and Metabolism Research Center, Shiraz University of Medical Sciences, Shiraz, Iran \\ ${ }^{2}$ Geriatric Research Center, Shiraz University of Medical Sciences, Shiraz, Iran \\ ${ }^{3}$ School of Dentistry, Shiraz University of Medical Science, Shiraz, Iran \\ "Corresponding author: Geriatric Research Center, Shiraz University of Medical Sciences, Shiraz, Iran. Email: ebrahimi_b@sums.ac.ir
}

Received 2020 March 18; Accepted 2020 March 24

\begin{abstract}
Background: The world is affected by the Corona Virus Disease 2019 (COVID-19). Because of their direct contact with patients, health workers, especially nurses, play critical roles in the prevention of the COVID-19 outbreak through proper care and preventive procedures.

Objectives: This study aimed to measure the awareness level of nurses in Shiraz, Iran, during the current COVID-19 outbreak.

Methods: A self-administered questionnaire containing knowledge questions was distributed to 85 participants to complete. Results: More than half of the nurses (56.5\%) had good knowledge about sources, transmission, symptoms, signs, prognosis, treatment, and mortality rate of COVID-19. The sources of information for the nurses were the World Health Organization and the Ministry of Health (55.29\%), social applications (48.23\%), and media (42.35\%).

Conclusions: Nurses had almost good knowledge of COVID-19. However, the WHO and the Ministry of Health still must provide more information for the medical staff for better control of the infectious disease.
\end{abstract}

Keywords: Iran, Nurse, Prevention, Shiraz, Coronavirus, Direct Contact, COVID-19, Health Staff

\section{Background}

The newest member of the coronavirus family (2019$\mathrm{nCoV}$ ) has been recently identified that results in acute and severe respiratory syndrome in humans (1). The first infected patient who had clinical manifestations such as fever, cough, and dyspnea (2) was reported on 12 December 2019 in Wuhan, China (1). Since then, 2019-nCoV has spread rapidly to other countries via different ways such as airline traveling and now, COVID-19 is the world's pandemic problem (3). Low pathogenicity and high transmissibility (4) are the two unique features of this new virus that distinguish it from other members of the coronavirus family such as SARS-CoV and MERS-CoV; this subsequently makes it difficult to control so that after passing more than three months of identifying the first infected human, the rate of infection and mortality is still high and COVID-19 has become a great public health concern in the world. No antiviral agents have been recommended so far (5) and prevention is the best way to limit the infection.

It seems that the current widespread outbreak has been partly associated with a delay in diagnosis and poor infection control procedures (6). As transmission within hospitals and protection of healthcare workers are important steps in the epidemic, the understanding or having enough information regarding sources, clinical manifestations, transmission routes, and prevention ways among healthcare workers can play roles for this gal assessment. Since nurses are in close contact with infected people, they are the main part of the infection transmission chain and their knowledge of 2019-nCoV prevention and protection procedures can help prevent the transmission chain. Iran is one of the most epidemic countries for COVID-19 and there is no information regarding the awareness and attitude of Iranian nurses about this infectious disease.

\section{Objectives}

The purpose of this study was to assess the knowledge, attitude, and behavior of the nurses concerning COVID-19 that is a helpful approach to upgrade the prevention and control procedures in similar situations using past preventive efforts. 


\section{Methods}

\subsection{Study Design and Data Collection}

To prevent the 2019-nCoV outbreak through droplets and contact, we used online software to design an electronic web-based questionnaire for collecting data over 80 hours (March 4, 2020, to March 8, 2020). The questionnaire was available to the participants through social media (WhatsApp and Instagram). Our study participants included nurses working in the hospitals dedicated to the admission and hospitalization of COVID-19 patients. Participation in this study was voluntary and the identification information of participants was not recorded anywhere on the questionnaire.

\subsection{Questionnaire and Data Processing}

The questionnaire was divided into three different parts. The first part included demographic data of the participants (sex, age, education level, and work experience). The second part evaluated the nurses' anxiety regarding their or their family infection with 2019-nCoV. The third part of the survey evaluated the knowledge of participants about COVID-19. In this part of the questionnaire, according to the information and recommendations of the WHO about the virus, we asked for the knowledge of participants towards 2019-nCoV sources, transmission, symptoms, signs, prognosis, treatment, and mortality rate (four Yes/No or I don't know questions and eight multiple-choice questions). Our questionnaire had two questions about the role of nurses in reducing the prevalence of COVID-19. The knowledge scores ranged from 7 to 24 and a score of less than cutoff $(<16)$ was designated as acceptable knowledge and more than cutoff $(\geq 16)$ was regarded as good knowledge.

\subsection{Data Analysis}

The coded data were analyzed using SPSS 22 and the forms with considerable missing data were excluded. Descriptive statistics were used to describe the quantitative and categorical variables. Continuous variables were expressed as mean \pm standard deviation (SD) and the $t$ test at the 0.05 significance level was used to compare different factors between different groups.

\section{Results}

\subsection{Demographic Characteristics of Participants}

Table 1 shows the demographic characteristics of the participants. Out of 85 respondents, 73 (85.9\%) were female. More than $75 \%$ (64 persons) of the respondents were in the group of less than 40-years-old and 22\% (19 persons) were aged more than 40 years. Concerning the education level, 11 out of 85 (56.3\%) participants had a high school diploma or less, more than half of them (67\%) had associate's or bachelor's degrees, and 20\% had master degrees.

\begin{tabular}{|c|c|}
\hline Variables & Number of Respondents (\%) \\
\hline \multicolumn{2}{|l|}{ Sex } \\
\hline Male & $12(14.1)$ \\
\hline Female & $73(85.9)$ \\
\hline \multicolumn{2}{|l|}{ Age } \\
\hline Less than 40 years & $46(75.3)$ \\
\hline More than 40 years & $19(22.4)$ \\
\hline \multicolumn{2}{|l|}{ Education level } \\
\hline High school diploma or less & $11(12.9)$ \\
\hline Associate's or bachelor's degrees & $57(67.1)$ \\
\hline Master's degree or above & $17(20.0)$ \\
\hline \multicolumn{2}{|l|}{ Work experience } \\
\hline Less than 5 years & $35(41.2)$ \\
\hline 5 - 15 years & $26(30.6)$ \\
\hline 15 - 25 years & $24.7(2.15)$ \\
\hline More than 25 years & $3(3.5)$ \\
\hline
\end{tabular}

Table 1 provides data regarding work experience; $41.2 \%$ of the participants had less than five years' work experience, 30.6\% between 5 and 15 years, 2.5\% between 15 and 25 years, and $3.5 \%$ of them had more than 25 years' work experience. None of the participants had COVID-19 or have had diagnostic tests and only one (1.17\%) person knew some people in her/his family who were infected with 2019-nCoV (Table 2).

\begin{tabular}{|c|c|c|}
\hline & Yes, No. (\%) & No, No. (\%) \\
\hline Being affected by the virus & $0(0)$ & $85(100)$ \\
\hline Having done diagnostic tests & $0(0)$ & $85(100)$ \\
\hline Knowing someone affected by the virus & $1(17.1)$ & $84(83.98)$ \\
\hline
\end{tabular}

\subsection{Anxiety Level of Participants}

Figure 1 shows the data of the participants' self-report of anxiety about the infection. The mean anxiety score was $6.02 \pm 2.6$ and their score of anxiety about their family infection was $6.87 \pm 2.8$.

\subsection{Knowledge Level of Participants}

The overall knowledge score of nurses was $16.35 \pm 3.3$. About $18.82 \%$ of the respondents knew the coronavirus family before the 2019-nCoV infection begins. Figure $2 \mathrm{~A}$ shows the percentage of different information resources about this family of viruses. Social applications were the first resources (52.94\%), followed by the Ministry of Health, 


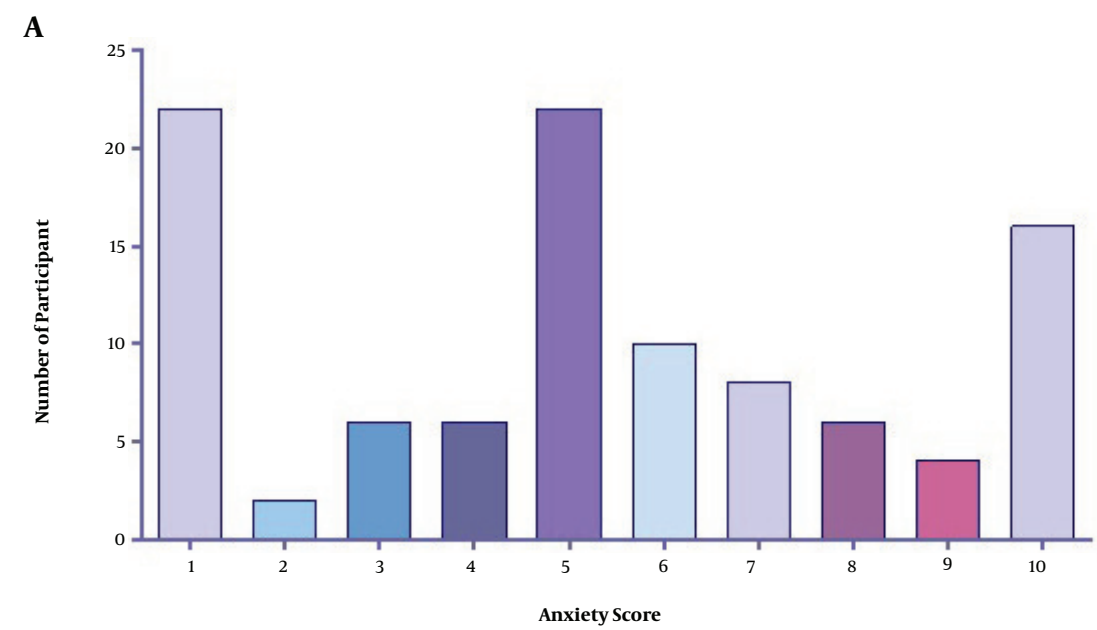

B

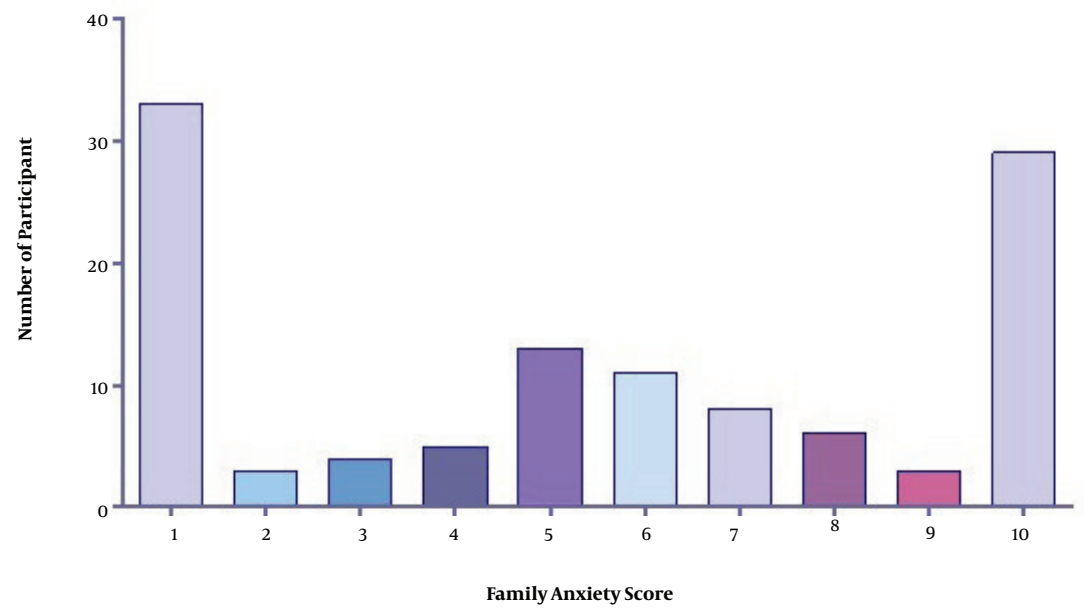

Figure 1. Corona-induced anxiety data; A, level of anxiety for self-infection; B, level of anxiety for family infection

the World Health Organization, and the media (51.72\%). The important point is that the World Health Organization and the Ministry of Health were the most common sources of information about 2019-nCoV (55.29\%), followed by social applications (48.23\%), and media (42.35\%). The majority of the respondents (94.11\%) regarded COVID-19 as contagious and $47.05 \%$ knew initial related symptoms such as fever and cough, and $12.94 \%$ of them knew advanced symptoms such as dyspnea. Moreover, $85.88 \%$ of the nurses had correct information about the source of infection, while $14.12 \%$ did not have the correct information. Besides, $68.23 \%$ of the participants had the best awareness of prevention methods and $31.77 \%$ had lower responses. In addition, $20 \%$ of the respondents were aware that the period of incubation for COVID-19 is about 2 - 28 days, while $58 \%$ answered 2 - 18 days.
Assessing the scores of questions showed that the mean score of knowledge was $16.35 \pm 3.3$ (out of 24); $56.5 \%$ of them had satisfactory knowledge (score $17.87 \pm 1.98$; more than the cutoff point) and $43.5 \%$ had a knowledge score of lower than the cutoff point (score 11.88 \pm 2.5 ) (Figure 2).

Table 3 shows the correlation between stress and knowledge of Corona and demographic characteristics. The stress level (on a 1 - 10 scale) did not have a significant correlation with both sex and work experience. Also, we found no significant correlation between knowledge, work experience, and education level. Finally, 75.29\% agreed that healthcare workers should be more involved and $92.94 \%$ agreed that their information should be updated to reduce the prevalence of the infection, while oth- 
A
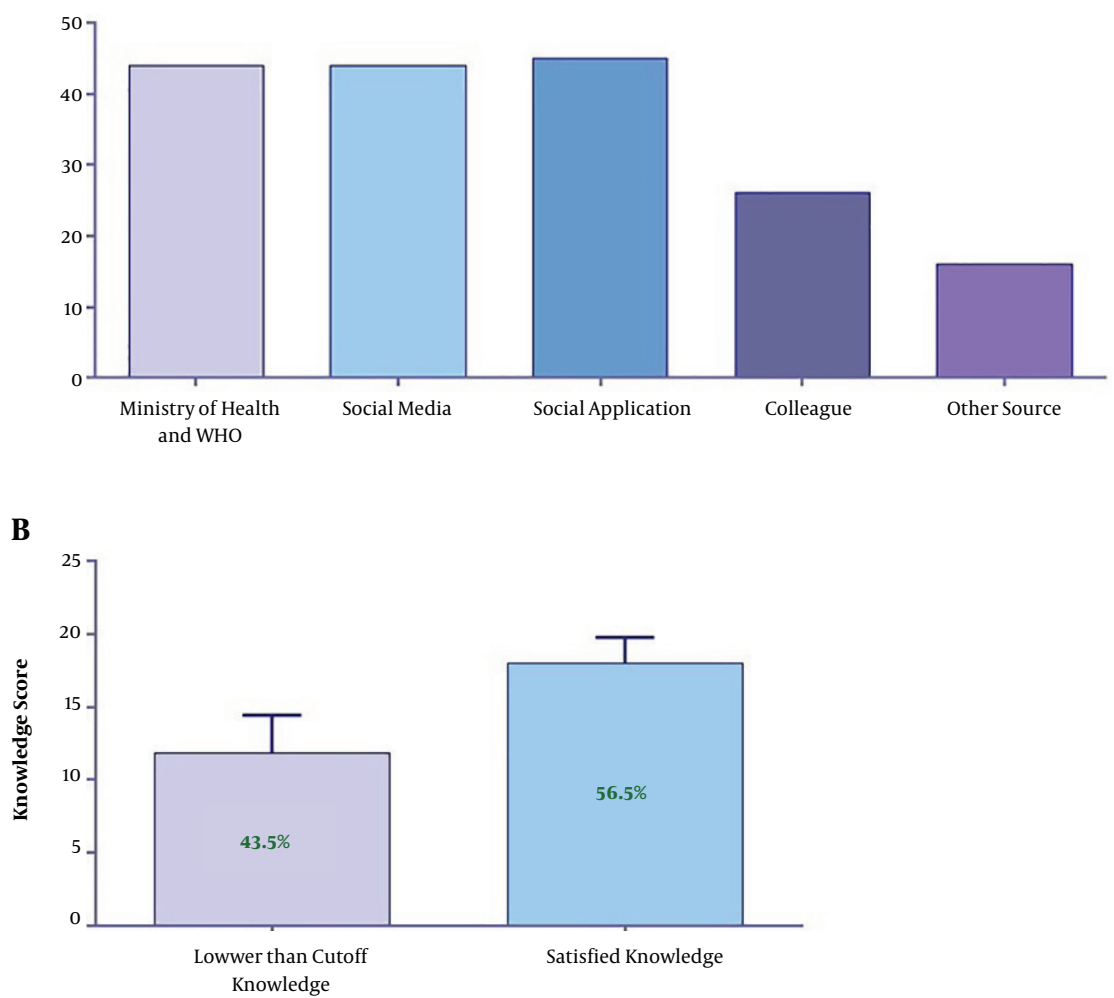

Figure 2. Results of Corona information; A, information resources; B, knowledge score

ers did not.

\section{Discussion}

Nowadays, COVID-19 is a life-threatening agent with the worldwide spread and it has become an international concern. This disease was first reported on 12 December 2019 from Wuhan (1). Due to the virus outbreak (4), more than 150 countries are currently infected and this virus's pandemic is a global emergency (7). Health workers, especially nurses, have close contact with infected patients and have a decisive role in infection control (8). In our country, Iran, as one of the top 10 countries that have the highest incidence of infection, assessing the level of nurses' information about COVID-19 can be an effective step in controlling the disease. The current study of 85 nurses showed their anxiety for themselves and their family affliction with COVID-19. Haung and Zhao in a study conducted at the time of the COVID-19 outbreak in China found high levels of anxiety among healthcare workers compared to others (9). In another study in Saudi Arabia, a high level of anxiety about MERS infectious disease was shown in medical students (10). The probable reasons for almost high anxiety may be the worry about being infected, the difficulty in the control of the epidemic, and the shortage of medical facilities across the country.

This study showed that the awareness of this sample of Iranian nurses was good regarding COVID-19 infection during the current outbreak so that more than half of (56.5\%) the nurses had good knowledge (more than the cutoff point) about the disease and interestingly, most of them rated their information as high as 6.12 (range of 1-10). Having sufficient knowledge may reflect the successful distribution of information about COVID-19 by different media. These results are in line with a study that revealed good knowledge and positive attitude among healthcare workers towards MERS (11) and also consistent with another study by Alqahtani (12) among 418 health college students in Najran, Saudi Arabia. Our results showed that nurses obtained their information through various media such as credible websites, WhatsApp, and TV. The widespread use of the internet and its availability to wider sectors of society have made it a major source of information for the population and nurses as a member of the population use this 
Table 3. Correlation Between Stress and Knowledge of Corona and Demographic Characteristics

\begin{tabular}{|l|c|}
\hline \multicolumn{1}{|l|}{ Anxiety } \\
\hline Lork experience & \\
\hline Less than 5 years & $5.77 \pm 2.9$ \\
\hline 5 - 15 years & $6.19 \pm 2.4$ \\
\hline 15 - 25 years & $5.90 \pm 2.3$ \\
\hline More than 25 years & $8.33 \pm 2.8$ \\
\hline Sex & \\
\hline Male & $5.83 \pm 3.0$ \\
\hline Female & $6.05 \pm 2.5$ \\
\hline Knowledge & $5.32 \pm 1.8$ \\
\hline Work experience & Knowledge \\
\hline Less than 5 years & \\
\hline 5 - 15 years & $6.28 \pm 1.9$ \\
\hline 15 - 25 years & $5.96 \pm 1.6$ \\
\hline More than 25 years & $5.95 \pm 2.1$ \\
\hline Education level & $7.00 \pm 2.6$ \\
\hline High school diploma or less & \\
\hline Associate's or bachelor's degrees & $7.27 \pm 1.6$ \\
\hline Master's degree or above & $5.96 \pm 1.8$ \\
\hline
\end{tabular}

information source as others do. Similar to our findings, other studies reported that participants usually obtained their information about infectious diseases through the internet and watching TV(13-15). The total knowledge score was not affected by age and education level and it was not significantly different between nurses with less or more work experience. In line with our study, the results of Saudi Arabian research on students from different majors and different educational backgrounds did not show the significant effect of age and education level on their information (7). In this regard, the generalized overbreak and high rate transmission of COVID-19 in the world might have increased the nurse's attention and knowledge of this pandemic disease.

\subsection{Conclusions}

Nurses had almost good knowledge about COVID-19. However, more information still must be provided by the WHO and the Ministry of Health for medical staff to mediate the better control of the infectious disease.

\section{Acknowledgments}

This work was done by the Geriatric Research Center and Endocrinology and Metabolism Research Center, Shiraz University of Medical Sciences, Shiraz, Iran.

\section{Footnotes}

Conflict of Interests: The authors report no conflicts of interest.

Funding/Support: None.

\section{References}

1. Zhou P, Yang XL, Wang XG, Hu B, Zhang L, Zhang W, et al. A pneumonia outbreak associated with a new coronavirus of probable bat origin. Nature. 2020;579(7798):270-3. doi: 10.1038/s41586-020-2012-7. [PubMed: 32015507]. [PubMed Central: PMC7095418].

2. Du Toit A. Outbreak of a novel coronavirus. Nat Rev Microbiol. 2020;18(3):123. doi: 10.1038/s41579-020-0332-0. [PubMed: 31988490]. [PubMed Central: PMC7073251].

3. Worldometers. COVID-19 coronavirus outbreak. 2020, [cited $2020 \mathrm{Mar}$ 5]. Available from: https://www.worldometers.info/coronavirus/.

4. Jiang S, Shi Z, Shu Y, Song J, Gao GF, Tan W, et al. A distinct name is needed for the new coronavirus. Lancet. 2020;395(10228):949. doi: 10.1016/S0140-6736(20)30419-0. [PubMed: 32087125].

5. Lu H. Drug treatment options for the 2019-new coronavirus (2019nCoV). Biosci Trends. 2020;14(1):69-71. doi: 10.5582/bst.2020.01020. [PubMed: 31996494].

6. Omrani AS, Shalhoub S. Middle East respiratory syndrome coronavirus (MERS-CoV): what lessons can we learn? J Hosp Infect. 2015;91(3):188-96. doi:10.1016/j.jhin.2015.08.002. [PubMed: 26452615].

7. Al-Mohaissen M. Awareness among a Saudi Arabian university community of Middle East respiratory syndrome coronavirus following an outbreak. East Mediterr Health J. 2017;23(5):351-60. doi: 10.26719/2017.23.5.351. [PubMed: 28730588].

8. Kharma MY, Alalwani MS, Amer MF, Tarakji B, Aws G. Assessment of the awareness level of dental students toward Middle East Respiratory Syndrome-coronavirus. J Int Soc Prev Community Dent. 2015;5(3):163-9. doi: 10.4103/2231-0762.159951. [PubMed: 26236674]. [PubMed Central: PMC4515797].

9. Huang Y, Zhao N. Generalized anxiety disorder, depressive symptoms and sleep quality during COVID-19 epidemic in China: A web-based cross-sectional survey. medRxiv. 2020. doi: 10.1101/2020.02.19.20025395.

10. Al-Rabiaah A, Temsah MH, Al-Eyadhy AA, Hasan GM, Al-Zamil F, AlSubaie $S$, et al. Middle East Respiratory Syndrome-Corona Virus (MERS-CoV) associated stress among medical students at a university teaching hospital in Saudi Arabia. J Infect Public Health. 2020. doi: 10.1016/j.jiph.2020.01.005. [PubMed: 32001194].

11. Khan MU, Shah S, Ahmad A, Fatokun O. Knowledge and attitude of healthcare workers about Middle East Respiratory Syndrome in multispecialty hospitals of Qassim, Saudi Arabia. BMC Public Health. 2014;14:1281. doi: 10.1186/1471-2458-14-1281. [PubMed: 25510239]. [PubMed Central: PMC4300996].

12. Alqahtani AS. Knowledge and attitude toward Middle East respiratory syndrome coronavirus among heath colleges' students in Najran, Saudi Arabia. Int J Commun Med Public Health. 2017;4(8):2641. doi: 10.18203/2394-6040.ijcmph20173153.

13. Tork HM, Mersal FA. Middle East Respiratory Syndrome-Corona virus: Knowledge and attitude of Qassim University students, KSA. Global Adv Res J Med Med Sci. 2018;7(4):90-7.

14. Kim JS, Choi JS. Middle East respiratory syndrome-related knowledge, preventive behaviours and risk perception among nursing students during outbreak. J Clin Nurs. 2016;25(17-18):2542-9. doi: 10.1111/jocn.13295. [PubMed: 27273475].

15. Chang SC. Raising clinical awareness for better dengue fever outbreak control. J Formos Med Assoc. 2015;114(11):1025-6. doi: 10.1016/j.jfma.2015.10.006. [PubMed: 26585886]. 